\title{
O FATO LINGÜÍSTICO E A CONSTITUIÇÃO DE UM SABER DE ENTREMEIO
}

\author{
Luiz Francisco Dias (UFPB)
}

Acredito que a maioria das pessoas, ao ouvir a palavra entremeio, a associa a algo como intervalo. Efetivamente. o dicionário registra essa acepçào. Entremeio entào seria o espaço entre dois fatos ou duas épocas, por exemplo. É como se estivéssemos apontando para algo situado entre o depois e o antes, ou entre o acima e o abaixo. Mas nunca para algo no seu exato tempo, ou no seu exato lugar. Nesse sentido, um saber de entremeio seria um saber fora do lugar.

Antes de avançar mais nos campos de sentido possiveis da palavra "entremeio" no dicionário, quero explorar um pouco a idéia do "lugar em que se situa um objeto da realidade". Por exemplo, onde esta o continente americano? Acima ou abaixo do continente europeu? liendo como referência o espaço sideral, depende da posição de observação em que o observador se encontra no universo. Mas é preciso um mapa que o localize enquanto "objeto pertinente". A fixação do lugar do continente americano foi regida pela História, que disciplina/regula/institui a pertinência dos objetos de conhecimento. Nesse sentido, Foucault (1986:104) afirmou que há "um 'referencial' que nào é constituido de 'coisas', 'fatos" 'realidades', ou de 'seres", mas de leis de possibilidade, de regras de existencia para os objetos que ai se encontram nomeados, designados ou descritos, para as relações que ai se encontram afirmadas ou negadas". Esse referencial. scgundo ele, forma a instância de diferenciação dos indivíduos ou dos objctos. Dessa forma, o lugar dos objetos não está inscrito neles mesmos. Há algo externo a eles que nos informa o seu lugar, que os corna visiveis, que os torna objetos de discurso, vale dizer, objetos da Ilistória.

Voltando ao dicionário, vejo que também se diz entremeio a "renda ou tira bordada entre duas peças lisas" (Aurélio). Ora, aquela representação meio negativa de entremeio desaparece em favor de uma outra, sendo que esta é bem mais simpática. A renda traz pertinência a um objeto que não é meramente duas peças lisas unidas 
entre si. Ela se destaca por fornecer uma identidade à toalha ou ao lençol. Nesse mesmo sentido, já se disse que a linha é mais importante que o tecido, embora não apareça, pois é com ela que se dá os contornos da roupa, vale dizer, é com ela que se fornece uma identidade a uma determinada roupa.

Por sua vez, Orlandi (1996) utilizou o termo "entremeio" para caracterizar a posição da Análise de Discurso frente às ciências sociais, de um lado, e à ciência lingüistica', de outro. No entender dela, a Análise de Discurso não teria um caráter interdisciplinar, pois não se constitui com base na recorrência aos conceitos de uma ou da outra. Ao contrário, ela procura intervir criticamente nessas duas ciências, deslocando conceitos como ideologia, sujeito, lingua, história. da forma como eles aparecem nas ciências sociais e na ciência lingüística. Vou aqui retomar a idéia de "entremeio", não especificamente para defender a posição da Análise do Discurso frente aos outros campos nas ciências humanas. Vou trabalhar com a idéia de um saber de entremeio. Pretendo mostrar que, independente dos "ismos", que freqüentemente nos separam, os estudos da linguagem teriam muito a ganhar caso empreendêssemos mais esforços no sentido de explorar melhor a concepção de entremeio.

Para isso, quero trazer aqui uma das intrigantes afirmações de Tom Jobim, sobre a diferença entre morar no Brasil e morar nos Estados Unidos.

(1) Morar nos Estados Unidos é uma maravilha, mas é uma merda. Morar no Brasil é uma merda, mas é uma maravilha.

Aparentemente, há contra-senso nessa afirmação, tendo em vista que temos duas proposições de identidades que se chocam entre si. Isto é, propõe-se a característica X ("ser uma maravilha") e logo após contrapòe-se essa à característica Y ("ser uma merda").

As construções com mas já foram bastante exploradas na história da lingüística. Principalmente no aspecto relativo à constituição de um contraste ou oposição entre as sentenças. Nesse sentido, vejamos os casos abaixo:

A referência de Orlandi recai principalmente sobre aquilo que se considera como "núcleo duro" da lingüística, constituído pelo conjunto dos estudos centrados na fonologia e/ou na morfossintaxe de uma lingua. 
(2) Os Estados Unidos são uma maravilha, mas eu não quero morar lá

(3) O Brasil é uma merda, mas o povo é uma maravilha

Em (2), temos um contraste entre a proposição de identidade ("ser uma maravilha") e uma conseqüência não esperada ("eu não quero morar lá”), que se opera a partir dessa proposição. Já em (3), opera-se um contraste entre a proposição de identidade ("ser uma merda") e um dos aspectos da totalidade fundadora da proposição ("o povo é uma maravilha").

Os estudos mais sofisticados sobre construções como essas foram os de O. Ducrot, para quem casos como esses envolvem um jogo polifônico no qual mais de um enunciador atua na constituição do sentido. Especificamente, em (2), um dos enunciadores discorda das conseqüências mais prováveis da proposição de identidade; e em (3), há uma discordância de apenas um dos elementos constitutivos da identidade. Em ambos os casos, tudo indica que a afirmação introduzida pelo mas não invalida as proposições de identidade. Dessa forma, podemos dizer que (2) e (3) são compatíveis, respectivamente, com $\left(2^{\prime}\right)$ e ( $\left.3^{\prime}\right)$ :

(2')Apesar de não querer morar lá, os Estados Unidos são uma maravilha

(3') Apesar do povo ser uma maravilha, o Brasil é uma merda

Mas em (1), ao contrário, a afirmação introduzida pelo mas parece provocar como efeito a invalidação da proposição inicial de identidade. Há outros enunciados que também desafiam os modelos convencionais de análise de construções com mas.

(4) Carla queria ser modelo, mas não é

(5) Eu não posso, mas vou emprestar-lhe o dinheiro ${ }^{2}$

Em (4), a sentença introduzida pelo mas, leva à produção de um efeito de oposição entre as duas sentenças. No entanto, a segunda sentença, num plano unidimensional de análise, nada mais faz do que afirmar uma conseqüência da primeira. Ela teria equivalência em (4'):

(4') Carla queria ser modelo. Nunca conseguiu

2 Enunciado mencionado na dissertação de Ana Berenice Peres Martorelli, defendida na UFPB, em janeiro de 2001. 
O enunciado (5) também nos causa estranhamento. A subordinada com mas traz uma afirmação sobre algo prefigurado como impossível na sentença principal. Pela visão produzida no plano da estabilidade lógica, teríamos algo como (5'):

(5') Eu não posso. Portanto, não vou emprestar-lhe o dinheiro

Dessa forma, a atuação do mas, enquanto elemento que participa de uma relação específica entre duas unidades sintáticas, parece ultrapassar em muito as relações semânticas que se estabelecem entre essas unidades. No entanto, não podemos negar que o mas tenha um papel específico na marcação de contraste entre as duas unidades (sentenças).

Assim sendo, a questão requer um tratamento que leve em conta a pertinência das construções com o mas na constituição da linearidade, isto é, no plano da organicidade sintática, de um lado; e, de outro lado, no plano do enunciável, isto é, do que pode ser dito (ou foi dito) em outras situações discursivas.

Quero, portanto, investir numa análise que possa contemplar dois planos de constituição do fato lingüístico: o plano da organicidade e o plano do enunciável ${ }^{3}$. Inicialmente, aquilo que chamei de "saber de entremeio" ganha especificidade na relação entre esses dois planos.

Nesse sentido, no plano do enunciável, há que se conceber, em (1), dois níveis de identidade relativamente ao Brasil: "ser uma merda" e "ser uma maravilha". Eles se concretizam em dois níveis de enunciação diferentes, por isso não se chocam, isto é, não constituem uma contradição. É no plano da organicidade, através do mas, que os dois níveis se cruzam, e passam a ser orientados para um mesmo ponto. Sendo assim, (1) é concebido como um texto. Construir um texto envolve, dentre outras coisas, produzir uma direção para o enunciável, orientar o enunciável para uma unidade. A unidade textual é resultado de um projeto de orientação do que deve/pode ser enunciado segundo determinadas condições de produção (Guimarães, 1987). Dessa forma, o papel do "mas", em (1), não é apenas o de aproximar os dois níveis de identidade, mas o de indicar o ponto de

Em Dias (2000) e Dias (2001), abordamos com mais detalhes esses dois planos de constituição do fato lingüístico. 
cruzamento a partir do qual eles passam a ser co-orientados, apesar de opostos.

Assim, no plano da organicidade, o mas foi ativado tendo em vista o papel de marcar contraste ou oposição; no plano do enunciável, por sua vez, o mas marca a orientação simultânea das duas identidades. Efetivamente, o efeito de unidade é reforçado no final do texto: "mas é uma maravilha". Temos aqui um efeito de fechamento. É algo que se fecha deixando expostas as aberturas. Na formulação textual, o mas denuncia essas aberturas/rupturas.

Em (4), também temos o mas no plano da organicidade, atualizando una memória de marcação de contraste ou oposição entre as duas sentenças; no plano, do enunciável, temos o mas marcando a discrepância entre dois níveís do enunciável: o do "querer ser" e o do "não ser".

Por sua vez, em (5), temos, no segundo nível do enunciável, o efeito de fechamento na sentença introduzida pelo mas: "vou emprestar-lhe o dinheiro". No entanto, no primeiro nível, há o registro de uma dificuldade virtualmente capaz de produzir uma negação ("não vou emprestar-lhe o dinheiro"). O mas atua no cruzamento entre uma situação virtual, no primeiro nível, e uma ação efetiva, no segundo nível. Assim, temos, como resultado desse cruzamento, a intensificação do "valor" dessa ação.

A oposição inerente às construções com mas não se constitui "a priori”. Ela se constitui na relação entre o orgânico e o enunciável na textualidade.

Inicialmente, propus que o saber de entremeio diz respeito à relação entre os planos da organicidade e do enunciável. Agora, podemos conceber também que o saber de entremeio diz respeito à relação discrepante entre os dois níveis de enunciação dentro do próprio plano do enunciável. Se a textualidade é a construção de uma direção de sentidos, é nessa construção que o problema do saber de entremeio é pertinente. Um saber de entremeio, portanto, se sustenta na tese de que o fato lingüístico tem uma realidade material, orgânica, e ao mesmo tempo uma realidade enunciativa, da ordem do simbólico. 


\section{REFERÊNCIAS BIBLIOGRÁFICAS}

DIAS, Luiz F. Gramática e ensino do português: abrindo horizontes. In: MOURA, D. (org.) Lingua e ensino: dimensões heterogêneas. Maceió: Edufal, 2000. p. 21-28.

DIAS, Luiz F. Observações sobre o fundamento do sujeito enquanto fato gramatical: uma perspectiva da enunciaçãc. Ensaios, Porto Alegre: Sagra Luzzato, n. 14, 2001 (no prelo).

DUCROT, Oswald. La pragmatique et l'étude sémantique de la langue. Letras de Hoje, Porto Alegre, v. 32, n. 1, 1997. p. 9-21.

FOỤCAULT, Michel. A arqueologia do saber. Rio de Janeiro: Forence-Universitária, 1986.

GUIMARÃES, Eduardo. Texto e argumentação. Campinas: Pontes, 1987.

ORLANDI, Eni P. Interpretação. Petrópolis: Vozes, 1996. 